\title{
Research on the Artistic Characteristics and Cultural Connotation of Women's Headgear and Hairdo of She Nationality in Fujian Province
}

\author{
$\mathrm{Xu}$ Chen \\ Clothing and Design Faculty \\ Minjiang University \\ Fashion Design Center of Fujian Province \\ Fuzhou, China
}

\author{
Jiangang Wang* \\ Clothing and Design Faculty \\ Minjiang University \\ Fashion Design Center of Fujian Province \\ Fuzhou, China \\ *Corresponding Author
}

\author{
Yonggui Li \\ Clothing and Design Faculty \\ Minjiang University \\ Fashion Design Center of Fujian Province \\ Fuzhou, China
}

\begin{abstract}
In this paper, the author takes women's headgear and hairdo of She nationality in modern times as the objects of study. With the historical materials and the literature, this paper investigates the characteristics of women's headgear and hairdo of She nationality in Fujian province, and analyzes the distribution and historical origin of women's headgear and hairdo of She nationality in Fujian province. Based on the theoretical foundation of semiotics and folklore, this paper analyzes the symbolic language and the implication of the symbols of women's headgear and hairdo of She nationality, and reveals the connotation of the ancestor worship, reproductive worship, migratory memory, love and affection contained in women's headgear and hairdo of She nationality. It shows the culture of headgear and hairdo of She nationality to the public.
\end{abstract}

Keywords-She nationality of Fujian province; female; headgear and hairdo; origin

\section{INTRODUCTION}

She nationality of Fujian province mainly distributes in Lianjiang county, Luoyuan county, Minhou county and Jin'an district of Fuzhou, Fujian province, and Gutian county, Feiluan township, Badu town, Xiapu county, Fu'an city, Fuding city and Zhangping county, Zhangpu county, Hua'an county of Zhangzhou city, Shunchang county of Nanping city, Shanghang county of Longyan city. The women of She nationality attach great importance to the headgear. The costumes and the headgear are the inscription of ethnic characteristics of She nationality, but also are significant sign different from other ethnic groups. The headgear of women

Fund Project: Science and Technology Planning Project (Project No. 2016-G-63) of Fuzhou, Social Science Project (MYS17031) of Minjiang University of She nationality includes the phoenix coronet and the hairdo worn by women. According to the scholar Pan Hongli's views, the hairdo of She nationality of Fujian province can be divided into Luoyuan style, Fuan style (including Ningde), Xiapu style, Fuding style (including Zhejiang and Anhui), Shunchang style, Guangze style and Zhangping style [1]. The author believes that the current women hairdo of She nationality of Fujian province only retain the four forms of Luoyuan, Fuan (the same with Ningde), the eastern Xiapu, the western Xiapu (the same with Fuding). Due to the blending of the She nationality in southern Fujian and western Fujian, Hakka and the local Han nationality, the costume culture has been tempered. At present, it is hard to find the existing headgear and hairdo during the research. The hairdo and headgear of women of She nationality of Fujian province can be divided into high style (such as Luoyuan style), bowl style (such as Fuan style and Fuding style, the western Xiapu style), dog head type (such as the eastern Xiapu style). The Luoyuan hairdo is high style. In the process of teasing hair, we need to use bamboo style. However, in the rest area, the hairdo is dominated by winding. The costumes of She nationality mainly have several national characteristics. First, in different regions, there is a clear distinction among clothing styles. And they have both of simple and complex items. Second, in different occasions, there is distinction between casual dress and splendid attire. The usual wears are generally easy to work. In major festivals, ancestral or festive occasion, people would have splendid attire. Third, due to different identities, there are significant differences in the wear of women's clothing. The headgear and hairdo of girls, unmarried women, married women and widowed women are significantly different. The culture of headgear and hairdo of She nationality is the inheritance and accumulation of the 
traditional headgear culture, and has unique artistic features of the southeast regions. The phoenix bun has become one of the national symbols of the She nationality. The most prominent feature of women's headgear of She nationality is "the unification of beauty and pragmatism, and the unification of beauty and significance". In social relations, it is the display and mark of national identity and etiquette system. In the spirits, it is the expression and manifestation of the pursuit of happiness for people. In practical function, it has the practical value and function, makeup effect, aesthetic taste and so on for human beings.

\section{THE ARTISTIC CHARACTERISTICS OF WOMEN'S HEADGEAR AND HAIRDO OF SHE NATIONALITY IN FUJIAN PROVINCE}

\section{A. Strong Color Contrast}

The most significant color of women's headgear and hairdo of She nationality is the red. The women of She nationality would tease red phoenix bun in front of the forehead, which contrasts the black. In the festival of She nationality, sacrificial activities, women of She nationality would wear exquisite phoenix costumes and phoenix bun shuttling in the streets. And it is beautiful. Also, the main color of the headgear of She nationality is silver. The phoenix crown of She nationality use a large number of silver. This silver plate is embedded in a variety of auspicious patterns. Women of She nationality would wear a phoenix crown. The silver hanging in front of women's face of She nationality has a unique lingering charm with the voice of dingdong.

\section{B. Rich Layers of Modeling}

The women's hairdos of She nationality have distinction between primary layer and secondary layer, distinction between former layer and latter layer, distinction between the virtual layer and actual layer. Luoyuan hairdo of She nationality can be divided into former layer and latter layer. The former layer is red or water red spiral coil. And the spiral coil is prominent. The latter layer is winding bamboo hairdo. And the hairdo is tall and live. The virtual and actual combination shows the beauty of women's headdress of She nationality. The style of women's phoenix crown of She nationality of Fujian province can be divided into three forms of bamboo tube (Luoyuan style), steeple style (Xiapu style) and peace top (Ningde style, Fuding style). In addition to the main body of the crown, the style of phoenix crown also contains the crown tail, flow spike, head hairpin, earrings, etc.. Ningde crown also contains the vertical curtain and beads "Fig. 1". In addition to the three-dimensional structure, it still has the external decoration. The scholar Jiang Bingzhao has described phoenix crown. "Women wear the crown on the top of the bun, and insert tail in the latter of bun. The chamilia beads are on the shoulders. The front and latter tassel is beautiful. [2]"

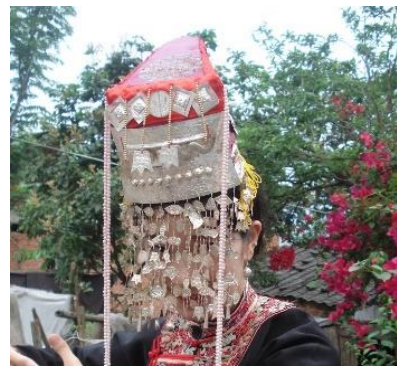

Fig. 1. Ningde phoenix coronet of She nationality.

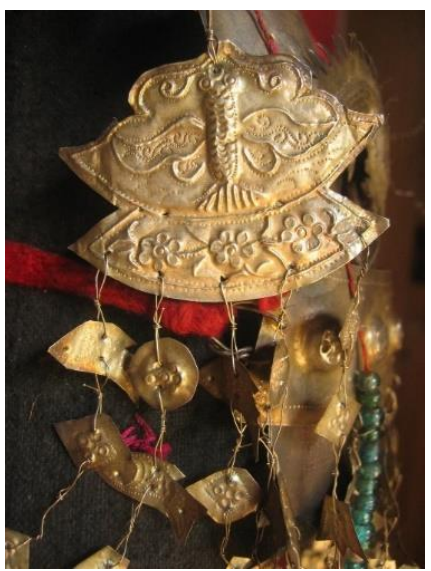

Fig. 2. The details of phoenix crown of She nationality.

\section{Rich Headgear Materials}

The materials for the production of phoenix crown include red raw silk cloth, silver flake, chamilia beads or plastic beads, bamboo tube and ramie cloth. The materials for coiled hairdo include wig, wool, bamboo and hairpin. These diverse and colorful materials form the headgear of She nationality.

\section{Auspicious Headgear Pattern}

The patterns on the phoenix crown of She nationality include dragon pattern, phoenix pattern, fish pattern, butterfly pattern, lotus pattern, seedpod of the lotus pattern, floral pattern and lion pattern, which show the longing for a better life of people of She nationality "Fig. 2". Most of people of She nationality in Fujian province live in vertical and horizontal mountains, near the sources of stream or the seaside. They live on fishing, growing tea and bamboo. Their living environment is closely related to fish. Therefore, they not only wear fish pattern, but also use the fish pattern to decorate the headgear. The fish-shaped ornaments hanging on the phoenix crowns are on behalf of the hope that women would have many children like fish. And they hope to reproduce the ability of fish to bless female reproductive capacity. And they hope the family prosperity with many children and grandchildren [3]. The phoenix crown of She nationality has transformed from wrapped bamboo crown to bamboo tube wrapped silver. The crown has more beautiful and precious decoration. And the lion pattern, peony pattern, lotus pattern and other patterns on the sliver are auspicious. 
They use the same pattern with the Han costumes. They have a strong sense of reproductive worship. The head hairpins in different shapes on the crown of the She nationality have the typical aesthetic and historical features of the Han culture. It has inserted the coins of Qing dynasty and gourd pattern. The lotus pattern and seedpod of the lotus pattern on the head hairpin have reproductive functions, which symbolizing the blessing of many sons and daughters of the She nationality. The totem worship of phoenix crown of She nationality is auspicious, which sends blessings to the people.

\section{THE CUltural CONNOTATION OF WOMEN'S HEADGEAR AND HAIRDO OF SHE NATIONALITY}

\section{A. The Headgear and Hairdo of She Nationality Is the Social Characterization of Totem Worship of She Nationality}

As the old saying goes, "skin is made by the parents." Hair is the crystallization of parents' blood and is a symbol of life. For women, hair is also an important part of women's charm. Women's hairdo of She nationality has always been one of prominent signs. First, from the perspective of historical records, She nationality has a deep tradition of worship of Panhu. And Yao nationality has the customs of headbands. It has same sources with She nationality. Fuding bowl type hairdo and headbands of Yao nationality have similar roles. However, people of Yao nationality use a cloth, and women of She nationality use the wig. Totem worship is the origin of headgear. Women's hairdo of She nationality is the totem worship of the social characterization. It has formed a typical gravity of rejection. As the worship of ancestors and other sacrificial activities become increasingly simple and even disappear, the women's hairdo commemorating Panhu is also fading out of the public view.

\section{B. Phoenix Crown of She Nationality Is the External Manifestation of the Female Worship}

Phoenix crown of She nationality is also closely related to female worship, which can be traced back to the worship of women in matriarchal clan society. It also derives from the female worship of She nationality from the customs and ideas of their ancestors third princess. This female worship affects the prosperity and development of She nationality.

It is said that the Queens sent a very precious crown and fairy clothes with gem to the third princesses, blessing daughter third princess bring good luck to life like phoenix. After the marriage, the third princess gave birth to three sons and a daughter. And the third princesses dressed the daughter as a phoenix [4]. In order to inherit the ancient legend, women of She nationality wear the phoenix-like crown. The special family status of women of She nationality also plays an important role in the inheritance of their costume culture. "History of the later Han dynasty — Dress culture" recorded that the ancients would wear antler when seeing the birds and beasts. Then, the ancients made the crown tassel. That was headgear. [5] It can be seen that the purpose of the Chinese ancients' creation of the crown is to imitate the head shape of birds and beasts in nature. They transformed it into a crown to be worn on the head. They decorate the crown with ribbons and beads, and then they stabilize it with the hairpin. Then, Luoyuan crown on the head of the women of She nationality indeed use bionic design to imitate the shape of the phoenix. And the headgear design is not only for ceremonial needs, but also plays a decorative role. And the headgear and hairdo of woman has transformed from the phoenix crown into phoenix head. And the source is traceable. For women of She nationality, the hairdo is the same as clothing. And it is only perfectly matched to represent the respects for ancestors. Elderly women of She nationality in Fujian province also retained the phoenix hairdo and phoenix clothing. If they don't have finished the washing, they are reluctant to take pictures. For the elderly, the phoenix hairdo has a certain national identity, but also reflects prominent position of the ancestors of the third princesses.

\section{Love Factor Is a Major Factor in the Inheritance and Development of Hairdo of She Nationality}

She nationality does not have their own words, but have their own unique language. March third of each year is Ukrainian festival of She nationality, but also is song competition day for men and women of She nationality. People of She nationality love singing. In marriage, funerals and festivals, they would express their own feelings through singing. Men and women who would sing will be called "talent" and will be respected by people. Unmarried women's hairdo also gives a courtship signal to unmarried men. And it facilitates them to identify and find singing partners. They can recognize the hairdo to distinct the laid-off or married women. And then, they can avoid embarrassment. Unmarried girls of She nationality have two silver hairpin in two bun. And they should take off one hairpin when they are married. Therefore, the hairdo of She nationality has typical identification function. Women could get people's attention through displaying their hairdo in social situations.

In short, women's headgear and hairdo of She nationality contains the connotation of history, totem worship, national integration, migratory memory, affection and other aspects. Therefore, the headgear and hairdo of women of She nationality has high standard and inclusiveness. And it has integrated the multiplication of strong national spirits and the national emotion from generation to generation.

\section{CONCLUSION}

The headgear and hairdo of women of She nationality include four different types of hairdo and three different types of phoenix crowns. Their formation is based on the national integration. It consists of the connotation of history, totem worship, national integration, migration memory, love and other aspects. Phoenix crown of She nationality truly reflects the ethnic folk beliefs, ideas and ideological consciousness from the hairdo, color, the specific ornaments, sewing, pattern, use and wearing methods. It also reflects the deepest psychological accumulation in the cultural structure. That is to say, it has some profound connection with folk psychology and national consciousness [6]. With the changes of the times and the accelerating pace of life, women's headgear and hairdo of She nationality and the wearing of 
the crown will inevitably have changes. We also have to accept the hairdo of She nationality which is like the hat in the modern times. This is the inevitable law of environmental adaptation to the development of the dress culture. What we can do is to retain its meaning in the inheritance of history rather than to simulate the shape of the past. And we should find out more things to inherit ethnic culture of She nationality and show the essence of ethnic culture of She nationality. Then, we could create women's headgear and hairdo of She nationality that the masses of She nationality would enjoy.

\section{REFERENCES}

[1] Pan Hongli. Analysis on clothing types of She nationality [J]. Fujian Wenbo, 1987 (2): 35.

[2] Jiang Bingzhao, History draft of She nationality, Xiamen University Press, 1988(09) p330, p339

[3] Chen $\mathrm{Xu}$, Chen Dongsheng. Analysis on the dress pattern of women of She nationality in Xiapu of Ningde, Journal of Textile Research, 2009 (3): 88-93.

[4] Qi Chunying. Chinese minority headdress culture [M]. Beijing: Religious Culture Press, 1996.02: 136.

[5] Fan Yezhuan. History of the later Han dynasty - Dress culture [M]. Li Yin, et al note, Shanghai: Zhonghua Book Company, 1965: 2829.

[6] Ye Dabing, Ye Liya. Folk custom on hairdo and headgear - China's hair culture. Shenyang: Liaoning People's Publishing House, 2000, 3 